\title{
The Groningen Ambulance Study
}

\author{
T Svilaas ${ }^{1}$, WA Dijk ${ }^{1}$, JP Busman $^{1}$, WRM Dassen ${ }^{2}$, R de Vos ${ }^{1}$, F Zijlstra ${ }^{1}$ \\ ${ }^{1}$ University Medical Center Groningen, Groningen, The Netherlands \\ ${ }^{2}$ Maastricht University, Maastricht, The Netherlands
}

\begin{abstract}
This paper describes the effects of a treatment protocol for patients with ST elevation myocardial infarction, which was introduced in 2004. The setup of the new approach is described. The principle goal is to minimize time between onset of symptoms associated with acute myocardial infarction and reperfusion through primary percutaneous coronary intervention. Preliminary results are discussed.
\end{abstract}

\section{Introduction}

Invasive therapeutic treatment through primary Percutaneous Coronary Intervention (PCI) of patients experiencing symptoms of acute cardiac ischaemia has become widely accepted [1,2,3].

Historically, in the Netherlands, patients with chest pain were transported to a community hospital. In case the diagnosis ST-elevation myocardial infarction (STEMI) was established and invasive therapeutic treatment was indicated, the patient underwent a second transportation to a PCI-hospital. Here another delay was introduced by a first assessment in the emergency department before transportation to the catheterization laboratory for invasive therapy.

Essential factors in the treatment of STEMI patients are among others the establishment of the correct diagnosis and the transportation time to a hospital capable of performing PCI $[4,5,6]$. The transportation of a patient involves the collaboration of different teams. Fast and reliable access to relevant information is essential.

Starting January 2004, a number of logistic optimization procedures combined in a single protocol were started to improve pre-hospital care for STEMI patients.

\section{Methods}

Table 1 is an illustration of the time delays involved historically from the moment a patient first experiences chest pain to the start of PCI.

\begin{tabular}{|c|l|}
\hline Time (min) & Event \\
\hline 10.10 AM & Chest pain \\
\hline 11.25 & Calling the emergency telephone (112) \\
\hline 11.34 & Arrival ambulance \\
\hline 11.55 & Departure to community hospital \\
\hline 12.09 & Arrival at community hospital \\
\hline 12.16 & Establishment of STEMI diagnosis \\
\hline 12.25 & Departure to PCI-hospital \\
\hline 12.34 & Arrival at PCI hospital \\
\hline 12.46 & Arrival at catheterization laboratory \\
\hline 12.54 & Coronary angiography \\
\hline 13.04 & First balloon inflation \\
\hline $\mathbf{2 h} \mathbf{5 4}$ & Total ischaemic period \\
\hline
\end{tabular}

Table 1: Typical time delays between onset of chest pain and PCI-treatment

The individual components of the delay were evaluated and investigated to optimize time and relevant information. All these processes resulted in the construction of the Groningen STEMI protocol. This protocol was implemented in January 2004.

\subsection{Time optimization}

As the case of the patient in Table 1 reveals, minimization of time delay between the onset of chest pain and PCI can be achieved at numerous stages. Each optimization has one or more prerequisites that have to be fulfilled.

Some time delays are difficult to shorten. For instance, the delay between symptom onset and warning the general physician or the ambulance service. This is dependent on patient factors. In the Netherlands a campaign has been started to educate the population on how to act when sudden chest pain is experienced.

Other steps can be bypassed, like the visit to the community hospital and the delay at the PCI hospital, where the patient is first transported to the emergency department instead of directly to the catheterization laboratory for invasive therapy. To accomplish this, the 
following steps were taken:

1. Training the ambulance personnel to be better aware of the symptoms of cardiac ischaemia.

2. Technical support through analyzing software in the defibrillators to determine the severity of myocardial ischaemia

3. In case of a large infarction direct transportation to the interventional hospital and in the interventional hospital by direct transportation to the catheterization laboratory.

4. Alarming the intervention team at the moment a positive diagnosis is established.

\subsection{Optimization of information processing}

Our hospital (the only one with PCI facilities) covers the north eastern part of the Netherlands. The province incorporates 575.000 inhabitants. It has 14 ambulance posts situated in such a manner that $95 \%$ of the province is in reach of an ambulance within 13 minutes. Three ambulance services are operating geographically divided.

Since 2004, the ambulances are equipped with defibrillators capable of recording, analyzing and broadcasting ECG's. A modified Simoons algorithm [7] (Figure 1) to assess the severity of acute myocardial ischaemia based on ST-elevation and depression was introduced to support the ambulance crew in the decision making process. The criteria were modified towards a more critical setting resulting in a lower percentage false negatives and a higher percentage false positives. The false positives are detected visually by the cardiologist in the PCI hospital, so no unnecessary invasive procedure is performed based on the computer assisted diagnosis. The capability of transmitting the 12 channel ECG recording to a fax is implemented with a fax-station at the Coronary Care Unit (CCU). This provides a second opinion and allows the PCI team to start preparations before the patient has arrived. The fax station is located in the CCU in order to guarantee 24 hour coverage by skilled personnel.

\footnotetext{
No WPW/LBBB/RBBB/IV-conduction block or pacemaker rhythm + $0.4 \mathrm{mv}<\left(\sum \mathrm{ST} \uparrow\right.$ in V1 - V6 $+\sum \mathrm{ST} \downarrow$ in II III aVF $)<0.6 \mathrm{mV} \rightarrow$ InferiorInfarction: advise for PCI

No WPW/LBBB/RBBB/IV-conduction block or pacemaker rhythm + $\left(\sum \mathrm{ST} \uparrow\right.$ in V1 - V6 + $\sum \mathrm{ST} \downarrow$ in II III aVF $) \geq 0.6 \mathrm{mV} \rightarrow$ Anterior Infarction: advise for PCI
}

Figure 1: Modified Simoons algorithm
The defibrillator has the capacity to store numerous data (ranging from the ID of the ambulance driver to the raw ECG data) on a memory card. These data are loaded into a database at the ambulance station and is used in this study to analyze the effects of logistic changes. Additional data like driver ID and general practitioner ID was used to join this database with our departmental information system INFOCOP [8] to link the data from both databases to the same patient. In the following chapters we will discuss the results of a first analysis of our data.

\section{Results}

In hectic situations concerning patients in need of instant help, administrating all data is understandably not experienced as a high priority task. Therefore, the accumulated data show a considerable number of missing or incorrectly coded items. Ambiguous information helped us to link the correct patients in both systems.

We analyzed 207 patients transported to our catheterization laboratory for PCI treatment in 2004, of which 103 were part of the STEMI protocol. In both groups $48 \%$ were female. The mean age in both groups was 63 years, ranging from 30 till 90 .

Table 2 presents an overview of the coronary arteries involved.

\begin{tabular}{|c|r|r|}
\hline $\begin{array}{l}\text { Primary } \\
\text { vessel }\end{array}$ & $\begin{array}{l}\text { \# of patients } \\
\text { no protocol }\end{array}$ & $\begin{array}{l}\text { \# of patients in } \\
\text { STEMI protocol }\end{array}$ \\
\hline LM & 1 & 1 \\
\hline RCA & 44 & 41 \\
\hline RDA & 48 & 47 \\
\hline RCX & 10 & 14 \\
\hline
\end{tabular}

Table 2: Target coronary arteries

Table 3 is an illustration of the time delays involved from the moment a patient first experiences chest pain to the start of the PCI treatment, after implementing the described STEMI protocol . 


\begin{tabular}{|c|l|}
\hline Time (min) & Event \\
\hline $10.10 \mathrm{AM}$ & Chest pain \\
\hline 11.25 & Calling the emergency telephone (112) \\
\hline 11.34 & Arrival ambulance \\
\hline & \\
\hline & \\
\hline 11.50 & Establishment of STEMI diagnosis \\
\hline 11.59 & Departure to PCI-hospital \\
\hline & \\
\hline 12.12 & Arrival catheterization laboratory \\
\hline 12.18 & Coronary angiogram \\
\hline 12.28 & First balloon inflation \\
\hline $2 \mathrm{~h} \mathrm{18}$ & Total ischaemic episode \\
\hline
\end{tabular}

Table 3: Time delays between onset of chest pain and PCI-treatment after implementing the STEMI protocol.

Table 4 describes the distances the ambulances had to cover. A number of patients took a detour along a community hospital. The mean distance in the STEMI group was $43 \mathrm{~km}$ and in the no protocol group $58 \mathrm{~km}$.

\begin{tabular}{|l|r|r|}
\hline Distance (km) & $\begin{array}{l}\text { \# of patients } \\
\text { no protocol }\end{array}$ & $\begin{array}{l}\text { \# of patients in } \\
\text { STEMI protocol }\end{array}$ \\
\hline unknown & 9 & 0 \\
\hline $0-9$ & 8 & 12 \\
\hline $10-19$ & 11 & 26 \\
\hline $20-29$ & 13 & 5 \\
\hline $30-39$ & 5 & 12 \\
\hline $40-49$ & 5 & 9 \\
\hline $50-59$ & 7 & 12 \\
\hline $60-69$ & 14 & 12 \\
\hline $70-79$ & 4 & 4 \\
\hline $80-89$ & 7 & 1 \\
\hline $90-99$ & 7 & 2 \\
\hline $100-$ & 14 & 8 \\
\hline & 104 & 103 \\
\hline
\end{tabular}

Table 4: Distances covered by the ambulances $(\mathrm{km})$

In Table 5 the mean time delay in the different stages of transport is displayed. The column on the left shows the mean delays for the no protocol group, the column the right the corresponding delays for the STEMI protocol group. As could be expected, the time spent in the ambulance and at the PCI hospital before first balloon inflation are considerably less for patients in the STEMI protocol due to the evasion of the community clinics and the emergency department in the PCI hospital.

\begin{tabular}{|l|r|r|}
\hline Stage & no protocol & STEMI \\
\hline Symptom onset - presentation & 84 & 91 \\
\hline Arrival ambulance & 8 & 8 \\
\hline Departure ambulance & 24 & 27 \\
\hline Arrival PCI hospital & 70 & 25 \\
\hline Start treatment (balloon inflation) & 67 & 53 \\
\hline Total elapsed time (min) & $\mathbf{2 5 1}$ & $\mathbf{2 0 3}$ \\
\hline Total elapsed time (h:min) & $\mathbf{4 : 1 1}$ & $\mathbf{3 : 2 3}$ \\
\hline
\end{tabular}

Table 5: Mean time delays in the different stages between the STEMI group and the no protocol group.

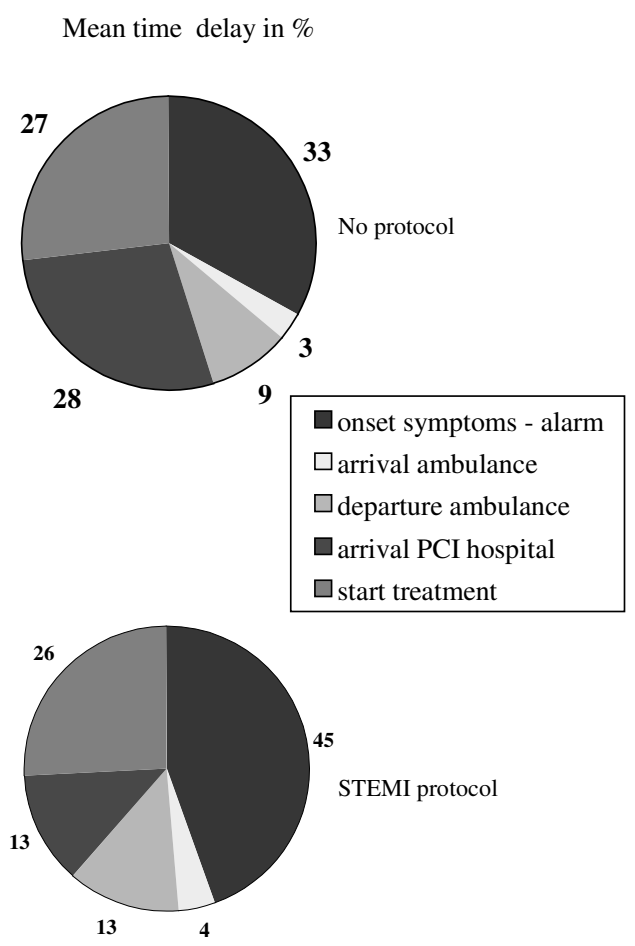

Figure 2. See text

Figure 2 illustrates the mean time delay for patients whether or not transported according to the STEMI protocol. Although the mean shortening in time is evident, 48 minutes, a large variation indicates a sub optimal adherence to the protocol. 


\section{Discussion and conclusions}

Due to the new protocol, a considerable shortening of the mean time interval between the onset of the symptoms and first balloon inflation at the PCI hospital has been achieved. The first stage, the one in which the patient experiences the myocardial infarction and warns the general physician, is still of considerable length. It even increased in the STEMI protocol group because of the extra procedures around transmitting the 12 lead ECG to the PCI hospital. Nation wide campaigns to inform the population may be a useful tool to address this problem. Considerable gain was reached in the other stages, mainly by bypassing the community hospitals leading to shorter distances and less patient transportation. The relative large variance suggests that the protocol has not always been strictly followed, possibly leading to premature conclusions. The year 2004 is therefore considered to be a pilot year to fine tune the protocol and to start incorporating the described approach to other ambulance services.

\section{Acknowledgements}

The authors are grateful to the Regional Ambulance Service Groningen for their support of this work.

\section{References}

[1] Zijlstra F, Hoorntje JC, de Boer MJ, et al. Long-term benefit of primary angioplasty as compared with thrombolytic therapy for acute myocardial infarction. $\mathrm{N}$ Engl J Med. 1999;341:1413-19.

[2] Keeley EC, Boura JA, Grines CL. Primary angioplasty versus intravenous thrombolytic therapy for acute myocardial infarction: a quantitative review of 23 randomised trials. Lancet 2003;361:13-20.

[3] Silber S, Albertsson P, Aviles FF, et al. Guidelines for percutaneous coronary interventions: the task force for percutaneous coronary interventions of the European society of cardiology. Eur Heart J. 2005;26:804-47.

[4] Terkelsen CJ, Lassen JF, Norgaard BL, et al.Reduction of treatment delay in patients with ST-elevation myocardial infarction: impact of pre-hospital diagnosis and direct referral to primary percutaneous coronary intervention. Eur. Heart J. 2005:26:770-777.

[5] Zijlstra F. Long-term benefit of primary angioplasty compared to thrombolytic therapy for acute myocardial infarction. Eur Heart J. 2000 Sep;21(18):1487-9.

[6] van 't Hof AW, Ernst N, de Boer MJ, et al. Facilitation of primary coronary angioplasty by early start of a glycoprotein $2 \mathrm{~b} / 3 \mathrm{a}$ inhibitor: results of the ongoing tirofiban in myocardial infarction evaluation (On-TIME) trial. Eur Heart J. 2004 May;25(10):837-46.

[7] Bouten MJM, Simoons ML, Hartman JAM, et al. An algorithm for prehospital thrombolysis in acute MI. Computers in Cardiology 1990; IEEE Computer Society Press, 279-281.

[8] Dijk WA, Haagen FDM, Infocop, Information System for Catheterized and Operated Patients. Computers in Cardiology 1984; IEEE Computer Society Press,241-244.

\section{Address for correspondence}

\author{
W.A. Dijk \\ Thoraxcenter \\ University Medical Center Groningen, University of \\ Groningen \\ Hanzeplein 1 \\ 9713 EZ Groningen \\ The Netherlands \\ W.A.Dijk@thorax.umcg.nl
}

